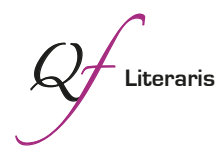

\title{
La censura de la corrección política: la traducción audiovisual a escena
}

\author{
Mabel Richart-Marset \\ Universitat de València-UVEG \\ mabel.richart@uv.es
}

\begin{abstract}
Resumen: Un aspecto muy importante de la labor del traductor o traductora está relacionado con aquellos factores que determinan su propuesta de traducción y es, en esa propuesta, donde se puede apreciar de forma clara tanto el ideologema, como el destinatario al que va dirigido el producto. En el caso de la traducción audiovisual (TAV), tal destinatario no puede ser identificado únicamente con la audiencia que asistirá a la proyección de la película, sino que engloba también el sistema moral de un momento histórico concreto. En la misma línea que Julia Kristeva, consideramos que la relación entre dos textos siempre se plantea en términos negativos, y es precisamente en la identificación de esa negación y en la transformación que se origina a partir de la misma, donde encontramos el gesto ideológico por excelencia. Este estudio trata de identificar dicha transformación en el espacio de la TAV y revelar actos de censura y manipulación de realidades descritas en el texto origen, que provocan a su vez, una imagen falsa de la realidad.
\end{abstract}

Palabras clave: autocensura; corrección política; ideologema; análisis genético del doblaje.

Abstract: A key aspect of the task of the translator is related to those issues that determine his or her proposal of translation, and in this proposal is where one can clearly see both the ideologeme and the addressee to whom the product is targeted. In the case of audiovisual translation (AVT) that addressee cannot be identified only by the audience that will watch the movie but also encompasses the morals of a particular moment in history. In line with Julia Kristeva, we think that the relation between two different texts always lies in negative terms and it is precisely in the identification of this denial, and in the transformation that originates from this same denial where we find the ideological gesture par excellence. This article seeks to identify that transformation in the context

》) Richart-Marset, Mabel. 2015. "La censura de la corrección política: la traducción audiovisual a escena”. Quaderns de Filologia: Estudis Literaris XX: 237-257. doi: 10.7203/qdfed.20.7539 
of AVT and to reveal acts of censorship and manipulation of the realities described in the original text, which in turn create a false image of reality.

Keywords: self-censorship; political correctness; ideologeme, genetic analysis of dubbing. 
I disapprove of what you say, but I will defend to the death your right to say it.

Evelyn Beatrice Hall (1868-1938)

\section{Introducción}

Mientras me encuentro escribiendo el último apartado de este artículo, una escalofriante noticia invade los medios de comunicación: el atentado perpetrado por tres terroristas yihadistas el pasado jueves 7 de enero, en la sede de la redacción del semanario satírico francés, Charlie Hebdo, en París. Como consecuencia de este brutal ataque, doce personas han perdido la vida, entre ellas, el director de la revista, Stéphane Charbonier.

Asisto, perpleja, a las declaraciones que la compañera de este último, Jeannette Bougrab, realiza en una cadena de la televisión francesa, donde asegura que siempre pensó que Charbonier iba a morir de la misma manera que el director de cine holandés, Theo Van Gogh. Recordemos que este cineasta fue abatido a tiros, y posteriormente acuchillado y degollado por un miembro de una organización islamista radical, en el año 2004, poco después de haberse emitido por la televisión pública holandesa su cortometraje Submission, Part 1.

Van Gogh dirigió este filme, de diez minutos de duración, a partir del guion de la escritora Ayaan Hirsi Ali, por aquel entonces diputada liberal-demócrata del parlamento holandés. En este corto, asistimos al testimonio de una actriz que narra en primera persona la historia de Aziz, una chica musulmana de 16 años, que fue forzada a casarse, para después ser maltratada físicamente por su marido, violada por su propio tío y, finalmente, acusada de adulterio. La guionista también está amenazada de muerte como consecuencia de la emisión del cortometraje, que, irónicamente, fue censurado un año más tarde en el Festival Internacional de Cine de Rotterdam. Y digo irónicamente, porque ese año la edición del festival estaba especialmente dedicada a la proyección de películas censuradas, y precisamente Submission, Part 1 iba a formar parte del panel titulado "Filmmaking in an Age of Turbulence", que abriría un debate posterior sobre la libertad de expresión.

Al hilo de este acontecimiento, el productor Gijs van de Westelaken explicó a los medios su decisión inamovible de retirar el cortometraje de Theo Van Gogh, declarando que él no quería "to take the slightest 
risk for anyone of our team" (nytimes.com, 31 January 2005) y reconoció retirar la proyección del corto cediendo a la presión del terror, justificando que él era un productor cinematográfico, y no un político o un policía antiterrorismo:

It's just the wrong moment right now [...] Does this mean I'm yielding to terror? Yes.

But I'm not a politician or an antiterrorist police officer; I'm a film producer" [...] Those behind Mr. van Gogh's killing, had already achieved what they wanted, to frighten the country (nytimes.com, 31 January 2005).

¿Acaso quiere decir van de Westelaken que las personas que, al igual que él, trabajan en cualquier medio de comunicación, llámese cine, televisión, prensa, etc., no tienen ninguna responsabilidad social a la hora de combatir un acto de censura? ¿Que todos los que no seamos "políticos" o "policías antiterrorismo" tenemos una especie de salvoconducto que nos dirige a una zona segura, donde, desde la inacción, estemos a salvo? ¿Desde qué posición van de Westelaken decide que es un mal momento para la exhibición del filme, erigiéndose él mismo en censor? ¿Es mejor, entonces, auto-engañarnos y tratar de ocultar nuestra flagrante cobardía, con el estandarte de la protección a los demás? En definitiva, ¿tenemos por tanto que ceder a la "presión del terror", autocensurándonos? No creo.

De hecho, la postura de la guionista del cortometraje, Hirsi Ali, fue bastante distinta a la de su productor. Aunque esta tuvo que abandonar Holanda y marcharse a Estados Unidos para garantizar su seguridad, declaró estar escribiendo "a new film, Submission, Part II, and perhaps even three and four" (nytimes.com, 31 January 2005).

El artículo que presentamos a continuación trata sobre la censura en la traducción audiovisual en España, pero no sobre la censura que tuvo lugar durante la dictadura franquista en el pasado siglo. Sobre la censura durante el franquismo, ya sea en la traducción literaria, teatral o audiovisual, existe una extensa y valiosa bibliografía a la que remitimos desde estas páginas a la lectora o al lector interesados: (Ávila, 1997; Rabadán, 2000; Ballester Casado, 2001; Díaz-Cintas, 2001; Merino y Rabadán, 2002; etc.).

Este artículo trata, lamentablemente, sobre la censura que en la actualidad se ejerce a través de la traducción audiovisual en mi país. Todo 
el colectivo que trabajamos en la comunidad académica o profesional de la traducción audiovisual (en adelante TAV), ya seamos profesores, traductores, ajustadores, directores de doblaje, audiodescriptores, subtituladores, etc., tenemos la obligación profesional y moral (aunque no seamos ni políticos ni policías antiterrorismo) de velar por una traducción sin censura, porque al hacer esto estaremos, sin ninguna duda, protegiendo a nuestra sociedad.

Ya en trabajos anteriores (Richart, 2009, 2012, 2013), denunciábamos la censura constante y continuada en el tiempo, que sufrimos año tras año, los investigadores y las investigadoras de TAV cuando intentamos acceder a la documentación generada, por ejemplo, en el proceso del doblaje de cualquier filme extranjero al español. Las puertas de numerosos estudios de Madrid y Barcelona (donde se concentran el mayor número de estudios de doblaje) se van cerrando una tras otra, guardando celosamente bajo llave las versiones traducidas, ajustadas y dobladas de cualquier guion original, e impidiendo, con este proceder, el acceso democrático del público a esos documentos. Se constataba en aquellas páginas, la existencia de una caja negra del doblaje que necesitaba ser abierta como en el caso de los aviones siniestrados, para descubrir la verdad sobre todo lo acontecido en la cadena de doblaje:

en el estudio del doblaje existe también una caja negra, apenas mencionada en los estudios, a veces entrevista y, desde luego, muy pocas veces exhibida [...]. Dicha caja tiene una existencia documental, textual, testimonial, que por razones de política empresarial, u otras, se oculta, se guarda bajo secreto y se impide el acceso democrático. Dicho de otro modo: la caja negra del doblaje es un archivo oculto a la mirada del especialista y del público en general (Richart, 2012: 8).

Señalábamos también que el método de análisis de superficies (utilizado por la mayoría de los investigadores en materia de TAV) entre la versión original de un filme y la versión doblada al español que llega hasta nuestros oídos en la sala de cine, aunque válido para identificar y detallar, por ejemplo, las distintas técnicas de traducción operadas, se tornaba del todo insuficiente para dar cuenta de lo que realmente había sucedido en el trasvase de una L1 a una L2, comportando así graves deficiencias en la aproximación al doblaje: 
[...] la indagación en el fenómeno del doblaje, así como el material al que tuvimos acceso después de una ardua pesquisa, nos puso ante los ojos el siguiente hecho: si a la hora de estudiar la traducción-doblaje [...] únicamente teníamos en cuenta el texto inglés de partida, tal y como aparece en el mismo filme, y el texto español meta, tal y como se encuentra también en el filme, estábamos escamoteando una parte esencial de esa labor, que corresponde a los pasos que llevan de un lugar a otro. [...] Entre el texto de partida y el texto meta había un silencio en blanco, un paréntesis, un anacoluto, que no nos iba a dejar dar cuenta en profundidad de lo que había ocurrido en el movimiento que lleva desde un punto a otro punto. Nos dimos cuenta, además, de que ese había sido el proceder en la mayor parte de los estudios sobre el doblaje [...], de que a pesar de su indudable valía en el plano de los estudios descriptivos de la traducción, en las propuestas de metodología de análisis, en la concretización de las normas que están en la base de esa clase de traducción, en tales casos el silencio en blanco, la caja negra en fin, seguía sin abrirse, sin ser estudiada, y ello comportaba indudables deficiencias en la aproximación al fenómeno del doblaje (Richart, 2012: 12).

Reivindicábamos también entonces, y seguimos haciéndolo ahora desde estas páginas, la absoluta necesidad de lo que bautizamos en su día como "análisis genético del doblaje" -y no solo reivindicamos la necesidad de un análisis genético en la modalidad del doblaje, sino también la necesidad de un "análisis genético" en el resto de modalidades de traducción audiovisual-, el cual se fundamenta en la necesidad de contar con el archivo íntegro de todo el proceso llevado a cabo en estas últimas.

El análisis genético es, al mismo tiempo, un análisis descriptivo y un análisis ideológico, en la medida que trasciende los límites de lo descriptivo, pues junto a la preocupación por la realidad de las trasformaciones textuales, le interesa, y mucho, responder a la pregunta de a qué o a quién sirven esas transformaciones. Estamos convencidos, a pesar de que somos conscientes de la dificultad que reviste acceder a este archivo íntegro, y, a pesar de que no siempre es posible, de que es el único método de análisis que garantiza una transparencia casi absoluta de todo el proceso llevado a cabo durante el doblaje o subtitulación de un texto audiovisual, puesto que estudia de manera individual cada uno de los 
documentos generados por cada agente ${ }^{1} \mathrm{y}$ responsabiliza a cada cual de las decisiones tomadas.

Y para probar la validez del análisis genético, en cuanto método de análisis ideológico, capaz de desvelar quién ha sido el agente responsable del acto de censura y los motivos que lo han llevado a cometerlo, vamos a analizar en este artículo una escena, extraída de la película de animación Shrek the Third/Shrek Tercero (2007, Chris Miller \& Raman Hui), donde sí pudimos aplicar el método del análisis genético del doblaje, ya que se nos facilitó el acceso al archivo íntegro de la cadena de doblaje (no se nos proporcionó, en cambio, el archivo íntegro del proceso de subtitulación).

\section{Censura y traducción audiovisual}

Empezaremos haciendo un breve repaso panorámico de las distintas definiciones que del término censura se han dado en algunos de los diccionarios más consultados, tanto en lengua española como en lengua inglesa.

El diccionario de la $R A E$ define censura en su segunda acepción como el "dictamen y juicio que se hace o da acerca de una obra o escrito" y en su séptima acepción como "la vigilancia que ejercen el yo y el superyó sobre el ello, para impedir el acceso a la conciencia de impulsos nocivos para el equilibrio psíquico" (RAE, vigésima primera edición, 1992). La versión en línea del diccionario VOX nos arroja la siguiente definición de censura en su segunda acepción: "autoridad pública, institución o entidad cuyo cometido es controlar la libre manifestación de pensamiento, ideas o información, aplicando un criterio ético, político o religioso" (2014: en línea).

Consultemos ahora la única acepción de censorship procedente del New Oxford American Dictionary: "the practice of officially examining books, movies, etc., and suppressing unacceptable parts" (2014: en línea), muy parecida a esta otra definición del Merriam-Webster dictionary: "the system or practice of censoring books, movies, letters, etc."

\footnotetext{
${ }^{1}$ Recordemos aquí que, según Geuss (1981: 1-2), las teorías críticas tratan de esclarecer los agentes que sostienen una acción humana determinada y de determinar a su vez cuáles son sus verdaderos intereses. Al mismo tiempo, son inherentemente emancipatorias, poseen un contenido cognitivo y son reflexivas.
} 
(2014: en línea). Por último, el Longman dictionary of Contemporary English define censorship como "the acts, practice, or duties of a censor" (1984).

Si miramos de cerca las definiciones acabadas de exponer, pronto advertiremos, que en la mayoría de ellas encontramos un doble denominador común: los objetos sobre los que se ejerce la censura por un lado: una obra o escrito, una obra destinada al público, libros, películas, material impreso en general, y los agentes que ejercen la censura por otro: el yo, el superyó, una autoridad pública, una institución o un censor. Agentes estos últimos que se encargan a su vez de ejercer vigilancia, de controlar la libre manifestación de ideas, de examinar, de suprimir, de hacer desaparecer las partes inaceptables.

Y precisamente al hilo de las definiciones anteriores, surgen de nuevo varias preguntas que me inquietan: ¿Quién en el circuito de la TAV decide sobre la existencia o no de partes inaceptables en un producto audiovisual, ya se trate de una película, de una serie de TV o de un documental? ¿Una institución, llámese productora, distribuidora, estudio de doblaje, ministerio de cultura, etc.? ¿Acaso un censor, llámese gobierno, ideología imperante, corrección política, productor de un filme, traductor, subtitulador, ajustador, directora de doblaje, asesor lingüístico, etc.? ¿Tal vez un Yo o un Superyó auto-censurador? ¿Cuándo podemos hablar de censura en TAV? Veámoslo.

Siempre hemos argumentado (Richart, 2009, 2012, 2013) que el doblaje -al igual que la subtitulación- es un fenómeno más complejo (si cabe) que la traducción ${ }^{2}$. Defendemos que la traducción es solo un paso (eso sí, esencial) dentro de las diferentes acciones que se realizan hasta llegar al producto final doblado o subtitulado, acciones que como hemos expuesto más arriba conforman el análisis genético. Teniendo en cuenta esto, el doblaje, en tanto traducción-moldeamiento-transformación, podría definirse como:

\footnotetext{
${ }^{2}$ En este sentido compartimos la opinión de O’Connell acerca de la imposibilidad de neutralidad en traducción: "[...] translation is never neutral. It is not possible to map ideas from one language to another without interpretation, without both loss and gain. Translation is a process which always involves decisions about what shade of meaning must be conveyed in the particular circumstances and what may, if necessary, be discarded" (2001: 1).
} 
un proceso de expansión cultural y comercial consistente en la traducción, moldeamiento y transformación de la dimensión verbal de un filme (y que puede introducir cambios en la percepción de la imagen) en sincronía con los labios de los actores y actrices, la dramatización, el tiempo de los discursos y la trama, y en cuya realización intervienen diferentes agentes (Richart, 2009: 123).

Esta definición sigue de cerca a la que dio Chaume cuando se refirió al doblaje como:

la traducció i ajust del guió d'un text audiovisual i la posterior interpretació d'aquesta traducció per part del actors, sota la direcció del director de doblatge i els consells de l'assessor lingüístic, quan aquesta figura forma part del procés. Tècnicament [...] es reemplaça la banda dels diàlegs originals per una altra banda en la qual aquests diàlegs s'enregistren traduïts en llegua meta i en sincronia amb la imatge. La característica més notable és que, per assolir l'efecte realitat, per convenció s'ajusta el text meta intentant d'aconseguir que respecte els moviments dels llavis dels personatges de pantalla en primers plans (la sincronia labial o fonètica), els moviments físics dels personatges de pantalla (la sincronia cinètica) i la durada dels enunciats dels personatges de pantalla (la isocronia) (2003: 17).

El doblaje puede ser considerado desde una triple perspectiva (Richart, 2009: 124-138): desde la óptica del receptor, desde la óptica del emisor y por último desde la óptica de la función comunicativa. Desde la óptica del receptor, el doblaje cumple una función suplementaria, consistente en hacer accesible cualquier producto audiovisual que, de otro modo, no podría ser comprendido por un público que desconoce la lengua de partida. En esto, el doblaje corre parejo con cualquier otro tipo de traducción, incluida la subtitulación (tanto interlingüística como para sordos o $\mathrm{SpS}^{3}$ ), que hace posible el acceso a un determinado producto cultural cuyo código lingüístico es ignorado por el receptor. El clásico

\footnotetext{
${ }^{3} \mathrm{Y}$ en relación con este punto vale la pena recordar que Fodor (1976:44-48) emplea la técnica de la lectura de labios empleada por las personas con discapacidad auditiva como una forma de estudiar la percepción de la relación entre sonido y movimiento del aparato fonador en la recepción de un filme doblado. En su conclusión leemos: "A person of normal hearing (and speech ability) carries on lip reading similar to that of a deaf person when he watches the actors and actresses in a synchronized film" (Fodor, 1976: 48)
} 
debate en torno a la subtitulación o doblaje tiene que ver precisamente con esta función suplementaria.

Desde la óptica del emisor, el doblaje responde a un interés cultural y económico, característicamente capitalista, de producir una mercancía en mayor o menor medida fetichizada ${ }^{4}$, con el fin de llegar al máximo número posible de personas y lograr una buena recaudación económica. Como escribió Ballester (1995: 5), "con el doblaje, EE. UU. podía, una vez más, mantener la dominación que había establecido en la era del cine mudo".

Por último, desde el punto de vista de la función comunicativa, el doblaje -como la subtitulación- tiene como finalidad prolongar o transformar la ideología que textualmente transmite un producto audiovisual (ya sea una película, una serie de televisión, un documental, etc.) y la industria que lo produce. Al decir "prolongar" o "transformar", nos referimos a dos hechos bien conocidos: por un lado, al intento de dejar los contenidos y las formas verbales tal y como vienen dados en el texto de partida cuando la relación entre las dos culturas no es problemática o incluso de dominante-dominado; por otro lado, al intento de censurar parte de los contenidos y las formas que pueden resultar problemáticos en la cultura política receptora. En este caso, la cultura receptora rechaza y elimina algunos elementos propios de la cultura emisora.

Fue Robyns (1994: 408-409) quien estudió las diferentes posturas que una cultura puede mantener frente a lo extranjero y señalaba cuatro posibles: a) la imperialista, que niega "lo otro" y lo transforma, b) la defensiva, que reconoce "lo otro" y también lo transforma; c) la transdiscursiva, que no se opone de forma radical y no lo transforma; y d) la defectiva, que demanda "lo otro" y no lo transforma. Una censura se identifica sin duda con la actitud imperialista.

Cuando utilizamos el concepto de ideología, lo hacemos con un sentido clara y heterogéneamente marxista. Sobre él proyectamos la idea

\footnotetext{
${ }^{4}$ Para la concepción de la mercancía como fetiche es obligada la referencia a Marx, quien en El Capital decía lo siguiente: “el carácter misterioso de la forma mercancía estriba, por tanto, pura y simplemente, en que proyecta ante los hombres el carácter social del trabajo de éstos como si fuese un carácter material de los propios productos de su trabajo, un don natural social de esos objetos y como si, por tanto, la relación social que media entre los productores y el trabajo colectivo de la sociedad fuese una relación social establecida entre los mismos objetos, al margen de sus productores" (Marx, 1867: 1-37 de la traducción española).
} 
bajtiniana expuesta bajo el nombre de Voloshinov (1929) según la cual el signo lingüístico (o icónico, tal y como sucede con la imagen) es el lugar donde se escenifica la lucha de clases o los conflictos sociales. Dicho de otro modo: la ideología no es una dimensión referencial que funcione al margen del signo, sino que posee características semióticas, se inscribe en el texto y da lugar a aquello que Julia Kristeva denominó "ideologema". La teórica búlgara asegura:

La confrontación de una organización textual (de una práctica semiótica) dada con los enunciados (secuencias) que asimila en su espacio o a los que remite en el espacio de los textos (prácticas semióticas) exteriores, será denominada un ideologema. El ideologema es esa función intertextual que se puede leer "materializada" en los diferentes niveles de la estructura de cada texto, y que se extiende a todo lo largo de su trayecto dándole sus coordenadas históricas y sociales (Kristeva, 1978: 147-148 de la trad. esp.).

Si el ideologema, como asegura Kristeva, es la confrontación entre una determinada organización textual y aquellos enunciados con los que se relaciona, entonces no resulta difícil comprender que toda traducción es el lugar donde el ideologema brilla con más potencia.

\section{El ideologema en Shrek Tercero: la vigilancia moral de "lo políticamente correcto"}

Scandura (2004: 125) afirma que la censura en la traducción audiovisual tiene lugar cuando el doblaje y la subtitulación "mask the deletion or replacement of erotic, vulgar or inconvenient sentences, allusions or references", y entre las razones por las cuales tiene lugar la censura distingue razones de índole política, religiosa, de corrección política y de autocensura (2004: 126):

1) Razones políticas 5 : en España tenemos un claro ejemplo con la dictadura franquista, donde el doblaje se utilizaba para ocultar el

\footnotetext{
${ }^{5}$ El documental Expediente 121: La censura en el cine (Lucía Herranz, 2007), producido por La Sexta en colaboración con Globomedia y presentado por Elsa Fábregas, actriz de doblaje desde 1935, es un valioso testimonio sobre las películas censuradas durante la dictadura franquista.
} 
diálogo original que no coincidía con la ideología del dictador y reemplazarlo por uno nuevo favorable a la ideología del régimen. En definitiva, era la modalidad de TAV que permitía una mayor manipulación de la versión original, ya que en la subtitulación ${ }^{6}$, por el contrario, el texto original podía oírse y siempre se corría el riesgo de que alguien entendiera la lengua.

2) Razones religiosas: en el conocido ejemplo del doblaje al español del filme estadounidense de Rouben Mamoulian Blood and Sand (1941), se producía un desplazamiento de sentido cuando Juan, el torero protagonizado por Tyrone Power, le preguntaba a su mujer Carmen qué hacía ella mientras él estaba en el ruedo. La respuesta de esta última era: "I sit by the window and count the seconds". El doblaje le hacía decir a Carmen, sin embargo: "Rezo continuamente a la Macarena", donde claramente advertimos que el texto de llegada ha negado y transformado (en el sentido de Robyns, 1994) el sentido del texto de partida, y que ese rechazo constituye el ideologema de ese texto. Para identificar más concretamente este ideologema, es necesario referirse a que esa negación-transformación estuvo determinada por el deseo franquista de reforzar la religión católica.

3) Razones de corrección política y 4) autocensura: estas dos últimas razones son las más pertinentes para el análisis de la escena de Shrek Tercero que vamos a llevar a cabo en este artículo. En dicho análisis tendremos la oportunidad de comprobar, por ejemplo, cómo un problema relacionado con la moralidad-legalidad del momento histórico en el que surge un texto audiovisual concreto determina la autocensura del propio agente traductor .

Empezaremos con el análisis de la escena de Shrek Tercero que detallamos a continuación. Tanto el guion original y la lista de diálogos en inglés, como los guiones traducidos y ajustados al español por los distintos agentes -y que nos van a permitir mostrar aquí parte del método del análisis genético del doblaje al que nos hemos referido más

\footnotetext{
${ }^{6}$ Díaz-Cintas, en su libro La traducción audiovisual: El subtitulado (2001), denuncia la marginación y censura a la que se sometió al subtitulado durante la dictadura franquista, donde la inmensa mayoría de películas procedentes del extranjero eran dobladas.
} 
arriba- se consiguieron gracias a las gestiones realizadas con el estudio de doblaje y a la inestimable colaboración de algunos de sus agentes.

3.1. Datos sobre traducción, doblaje, subtitulación, y distribución de Shrek the Third

\begin{tabular}{|l|l|}
\hline Título original/Título traducido & Shrek the Third/Shrek Tercero \\
\hline Género & Largometraje de animación \\
\hline Agente Director de doblaje & Gonzalo Abril \\
\hline Agente Traductora de doblaje & Sally Templer \\
\hline Agente Ajustador de doblaje & Gonzalo Abril \\
\hline Estudio de doblaje & Sonoblok (Barcelona) \\
\hline Agente Subtitulador & No se especifica \\
\hline Estudio Subtitulador & No se especifica \\
\hline Distribuidora para España & Paramount España \\
\hline Distribuidora original & Dreamworks \\
\hline
\end{tabular}

3.2. Breve descripción de la escena (TCR: 00:25:10-00:25:20)

Recordemos que al principio de esta película fallece el padre de Fiona, el monarca rana de Muy Muy lejano, y como Shrek y Fiona son los siguientes en la línea de sucesión al trono, les toca ahora a ellos gobernar el reino. Shrek, totalmente contrario a la idea de convertirse en rey, hará todo lo posible por encontrar al joven Artie ya que este último es el próximo en la línea sucesoria. En esta escena, Shrek, Asno y Gato se encuentran ante las puertas del instituto de Worcestershire, donde finalmente han localizado a Artie. Este ambiente les hace sentir incómodos, por las reminiscencias de su etapa escolar, y muy especialmente a Asno quien mantiene el siguiente diálogo con Gato: 
TCR Inicio-fin escena (00:25:10-00:25:20)

\begin{tabular}{|l|l|l|l|}
\hline PERSONAJE & \multicolumn{1}{|c|}{ VO } & \multicolumn{1}{c|}{ VD } & \multicolumn{1}{c|}{ VOS } \\
\hline Asno & $\begin{array}{l}\text { I really start to } \\
\text { feel nauseous } \\
\text { from memories } \\
\text { of } \text { wedgies and } \\
\text { swirlies. }\end{array}$ & $\begin{array}{l}\text { Solo de recordar } \\
\text { las bajadas de } \\
\text { pantalones ya } \\
\text { tiemblo. }\end{array}$ & $\begin{array}{l}\text { Odio recordar } \\
\text { cuando me } \\
\text { metían los } \\
\text { calzoncillos por } \\
\text { el culo. }\end{array}$ \\
\hline Gato & $\begin{array}{l}\text { But how did } \\
\text { you receive the } \\
\text { wedgies when } \\
\text { you are clearly } \\
\text { not the wearer of } \\
\text { the underpants? }\end{array}$ & $\begin{array}{l}\text { Pero icómo iban } \\
\text { a bajártelos si tú } \\
\text { nunca has usado } \\
\text { los pantalones, } \\
\text { pichurri? }\end{array}$ & $\begin{array}{l}\text { ¿Cómo podían } \\
\text { metértelos por } \\
\text { el culo cuando } \\
\text { está claro que no } \\
\text { llevas? }\end{array}$ \\
\hline Asno & $\begin{array}{l}\text { Let's just say that } \\
\text { something are } \\
\text { better left unsaid. }\end{array}$ & $\begin{array}{l}\text { Digamos que } \\
\text { hay cosas que es } \\
\text { mejor mantener } \\
\text { en silencio. }\end{array}$ & $\begin{array}{l}\text { Digamos que } \\
\text { ciertas cosas } \\
\text { es mejor no } \\
\text { decirlas. }\end{array}$ \\
\hline
\end{tabular}

Tabla 1. Reproducción tanto del guion original (VO) como de las versiones finales doblada (VD) y subtitulada (VOS) (las negritas son nuestras)

\subsection{El documento generado por el agente traductor:}

Wedgies $y$ Swirlies

Como podemos observar en este documento, la traductora Sally Templer ofrece varias propuestas de traducción al siguiente agente de la cadena, el agente ajustador y al mismo tiempo director de doblaje, Gonzalo Abril. Se trata de un texto precario, de un borrador con notas que irán moldeándose en las siguientes fases de la cadena de doblaje -y la traductora, consciente de la condición de borrador de su propuesta, introduce en el mismo documento de la traducción, una nota que advierte al ajustador de lo que ella considera un posible peligro-. Ahora bien, en este caso, las vacilaciones de la traductora no se deben a un problema lingüístico, sino a un problema relacionado con la moralidad-legalidad del momento histórico en el que se proyectó Shrek Tercero en España. 


\begin{tabular}{l}
\hline ASNO \\
¡Me da un mareo solo de recordar los chicles y los mocos pegados bajo \\
mi asiento! (LIT: ... recordar los tirones de calzoncillos y la cabeza metida \\
en el inodoro! -TÍPICAS BROMAS A NOVATOS / PERDEDORES-) \\
NOTA $\backslash^{*}$ HABRÁ QUE TENER CUIDADO CON EL TEMA DEL \\
BULLYING/ACOSO ESCOLAR YA QUE ESTÁ MUY CANDENTE Y \\
NO ADMITE MUCHAS BROMAS. POR ESO HE PUESTO LO DE LOS \\
MOCOS Y DEL CHICLE. \\
GATO \\
(LIT: Pero ¿cómo te tiraban de los calzoncillos cuando tú claramente no \\
llevas/gastas esa prenda?) Pero ¿cómo te sacabas los mocos si no tienes \\
dedos para hurgarte el hocico? \\
ASNO \\
$\backslash$ (OFF) Digamos (ON) que hay cosas de las que es preferible no hablar (o = \\
por las que mejor no adentrarse)”.
\end{tabular}

Tabla 2. Documento generado por la agente traductora respetando su formato (a excepción de la negrita, que es nuestra)

La traductora es consciente de que el destinatario o las instituciones legales pueden mirar con malos ojos esas alusiones al acoso escolar (bullying), de hecho, en su nota se lo advierte claramente al agente ajustador: "Habrá que tener cuidado con el tema del bullying ya que está muy candente y no admite muchas bromas", y es precisamente, esa posibilidad que teme la traductora, la que funciona como una forma de autocensura ${ }^{7}$. Tal y como pone de relieve en su texto, ella sabe que los wedgies y los swirlies nombran de una manera directa esas bromas pesadas consistentes en subirles los calzoncillos hasta introducirlos entre sus nalgas, o meterles la cabeza en el inodoro (respectivamente) a aquellos alumnos que son novatos o están marcados por su debilidad psíquica y/o física. ${ }^{8}$

\footnotetext{
${ }^{7}$ Martínez-Sierra alude también a la propia autocensura del agente traductor en su artículo "La traducción de nigger en Django desencadenado: un enfoque ideológico" (2015).

${ }^{8}$ Un "retrato" trágico de esta práctica se encuentra expuesto con toda su crudeza en el filme de Larry Clark Bully (2001).
} 
En este sentido, esos recuerdos de Asno pueden resultar excesivos si se tiene en cuenta que el público al que en principio está destinado este filme, es un público infantil y juvenil. Al menos eso es lo que la traductora ha podido pensar. Así pues, con el fin de atenuar o aminorar la crudeza de los actos nombrados directamente por las palabras "wedgies" y "swirlies", decide poner en su lugar los "chicles" y los "mocos" pegados debajo del asiento de Asno.

Dicho de otro modo, el texto español propuesto por el agente traductor al agente ajustador rechaza el texto inglés, lo niega y lo transforma, y esa negación-transformación, ese rechazo, en definitiva, tiene su origen en una vigilancia moral de lo "políticamente correcto".

Se trata de una restricción moral que está condicionando la labor de la traductora ${ }^{9}$. Es otro caso de ideologema: la censura moral provoca una negación-transformación en el texto de llegada, el miedo a la reacción del espectador y de la ley ante esa mención de actos vandálicos determina que en vez de hablar de "dar tirones a los calzoncillos" y de "meter la cabeza en el inodoro", se hable de chicles y mocos pegados bajo el asiento. Como señala Scandura con relación a la propia autocensura del agente traductor:

sometimes it is the translator who decides to modify certain elements because he or she feels they are not appropriate. Translators tend to think they should protect the audience, and so they believe they can determine what is right or what is wrong to communicate, regardless of what the spirit and manner of the original were (2004: 126, la cursiva es nuestra).

Sería difícil sostener que existe una correspondencia o equivalencia entre la expresión inglesa y la española, sería igualmente difícil no aceptar la existencia de una "manipulación" en el tránsito de un texto a otro. No obstante, lo que nos parece más notable de este caso es cómo el factor de la moralidad derivado de una legalidad y un estado de opinión respecto a unos hechos determinados, actúan como elementos determinantes de una traducción. De todos modos, el problema va más allá, porque si el bullying es una práctica que se da entre el alumnado de los colegios e institutos en Estados Unidos, ¿qué se gana con soslayarlo y ofrecer una

\footnotetext{
9 "Restricción" en el sentido en que Zabalbeascoa ha estudiado este problema (1994: 90-91).
} 
imagen del mundo no acorde con la realidad? A fin de cuentas, el filme estadounidense lo subraya, ¿por qué ocultarlo en el doblaje español?

El argumento es claro: la propuesta de traducción que acabamos de citar no solo manipula el texto de origen, sino que provoca una imagen falsa de la realidad. No sería nada descabellado referirse a ello en términos de "censura" (Richart, 2012: 180), en este caso la censura de "lo políticamente correcto", la censura, al fin y al cabo, de no poder llamar a las cosas por su nombre.

Lo cierto es que el acto de ocultamiento de una realidad descrita en el texto de origen, solo a duras penas puede considerarse como una regla plena, ya que no todo agente traductor se dejaría llevar por ella. Lo es en tanto la traductora que en palabras de Hatim y Mason (1997: 146) "acts in a social context and is part of that context"10 se la ha impuesto ocasionando, como comprobaremos más adelante, un resultado sorprendente en el doblaje.

\subsection{El documento generado por el agente ajustador:}

Sí a los wedgies, No a los swirlies

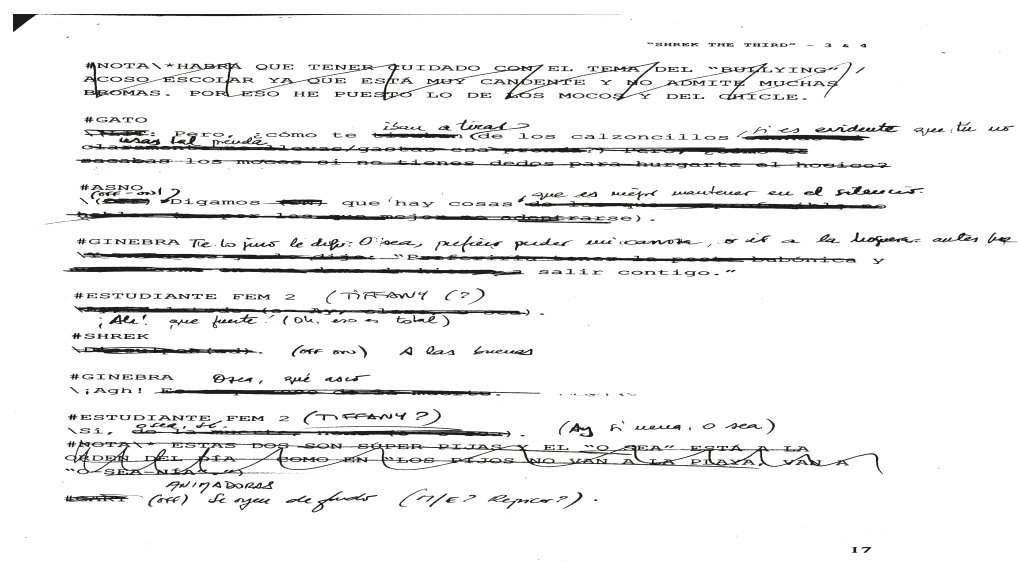

\footnotetext{
10 "the translator acts in a social context and is part of that context. It is in this sense that translating is, in itself, an ideological activity" Hatim y Mason (1997: 146).
} 
El documento de trabajo producido en el paso anterior por la traductora se convierte en la base a partir de la cual empezará la tarea del próximo agente, el agente ajustador. El moldeamiento que realiza este agente tiene un sentido muy preciso: se refiere al acto de embutir ${ }^{11}$ las diferentes secuencias lingüísticas proporcionadas por la traductora en los espacios y tiempos formados por los movimientos labiales de los personajes del filme y por la duración de los enunciados, entre otras cosas. Nos encontramos ante un paso más que supone una transformación de otro texto anterior. De ahí que suscribamos las siguientes palabras de Gambier (2002: 179) en tanto en cuanto se apliquen de una manera específica al doblaje:

Le chaine de transformations, aux macro- et micro-niveaux, sous la contrainte des idéologies, des canons esthétiques, des rapports de pouvoir et d'argent entre les agents engagés (producteurs, metteurs en scène, distributeur, etc.) n'est pas san rappeler la traduction perçue comme "reformulation" ou "manipulation" par André Lefevere (1992).

El ajustador no traduce, pues, sino que adapta, rechazando y transformando a su vez el texto proporcionado por la traductora. Vemos, en primer lugar, cómo tacha toda la nota de la agente anterior con respecto al "acoso escolar" y rechaza la propuesta de "los mocos y los chicles", impidiendo así la autocensura de la traductora con respecto a la palabra wedgies, la cual el ajustador mantendrá en la fase de ajuste: "tirar de los calzoncillos". Sin embargo, los swirlies ("la cabeza metida en el inodoro" de la que nos hablaba la traductora en su documento de trabajo) no correrán la misma suerte, y lejos de ser rescatados de las garras de la autocensura, seguirán negados (censurados), en esta fase de ajuste.

\subsection{El documento generado por el director de doblaje o "la bajada de pantalones"}

¿Cuál es el resultado final? En la consulta del documento dividido en takes y generado por el agente director de doblaje (quien junto con los actores, los asesores lingüísticos, los técnicos de sonido, etc., realizan

\footnotetext{
${ }^{11}$ De "operación de embutido" habla J. Lacan (1973) en su ensayo sobre Joyce y la metáfora.
} 
en un trabajo de sala el "documento final"'2), el espectador puede apreciar que el comentario original de Asno en relación a los wedgies y a los swirlies ha sido rechazado y transformado en este otro: "solo de recordar las bajadas de pantalones ya tiemblo".

Está claro que bajarle los pantalones a alguien es otra de las bromas pesadas que se puede poner en práctica entre los alumnos. En este sentido, el texto inglés y su versión española mantienen una determinada relación de equivalencia, podríamos incluso hablar de domesticación en la traducción. Sin embargo, convendremos en que lo que wedgies y "bajadas de pantalones" denotan son cosas opuestas. En el primer caso, se trata de subir, en el segundo de bajar (relación de antonimia, pues); en el primer caso se alude a una prenda interior como son los calzoncillos, en el segundo se nombra una prenda exterior como son los pantalones. De este modo, los rasgos "subir" e "interior" presentes en el texto de partida son los opuestos de los rasgos "bajar" y "exterior" del texto de llegada.

No sería muy descabellado hablar aquí de "traducción irónica" dado que la traducción dice lo opuesto del texto de partida. El hecho de nombrar los pantalones en vez de los calzoncillos puede alejar al espectador de las zonas genito-anales, pero paradójicamente lo acercan más por cuanto al bajar los pantalones el sexo y el culo pueden quedar a la vista.

El doblaje mexicano de esta misma secuencia encuentra, sin embargo, una expresión del todo equivalente ya que en México hay una expresión para designar el mismo fenómeno: "calzón chino". En efecto, hacerle calzón chino a alguien (en alusión a los luchadores de sumo) significa subirle los calzoncillos a alguien hasta que se le quedan introducidos entre las nalgas. En la versión doblada mexicana Asno dice lo siguiente: "hasta me frunzo de acordarme cuando me hacían calzón chino".

\section{Bibliografía}

Ávila, Alejandro. 1997. La censura en el doblaje cinematográfico en España. Barcelona: CIMS.

Ballester, Ana. 1995. The Politics of Dubbing. Spain: a Case Study. En Jansen, Peter (ed). Translation and the Manipulation of Discourse: Selected

\footnotetext{
${ }^{12}$ Para una descripción más detallada de la labor realizada por el conjunto de agentes del documento final, véase: Richart (2009: 153-154).
} 
Papers of the CERA Research Seminars in Translation Studies. Lovaina, CETRA: 159-182.

Ballester, Ana. 2001. Traducción y nacionalismo. La recepción del cine americano en España a través del doblaje, 1928-1948. Granada: Comares.

Chaume, Frederic. 2003. Doblatge i subtitulació per a la TV. Universitat de Vic: Eumo.

Díaz-Cintas, Jorge. 2001. La traducción audiovisual: el subtitulado. Salamanca: ediciones Almar.

Fodor, István. 1976. Film Dubbing: Phonetic, Semiotic, Esthetic \& Psychological Aspects. Hamburgo: Buske.

Gambier, Yves. 2002. Les censures dans la traduction audiovisuelle. TTR: traduction, terminologie, rédaction 15(2): 203-221.

Geuss, Raymond. 1981. The idea of a critical Theory. Habermas \& The Frankfurt School. Cambridge: Cambridge University Press.

Hatim, Basil \& Mason, Ian. 1997. The Translator as Communicator. Londres: Routledge.

Kristeva, Julia. 1978. Semiótica. Madrid: Fundamentos.

Martínez-Sierra, Juan José. (En prensa). La traducción de nigger en Django desencadenado: Un enfoque ideológico. En Frederic, Chaume \& Richart-Marset, Mabel (ed.) Prosopopeya. Revista de crítica contemporánea: Traducción, ideología y poder en la ficción audiovisual, $\mathrm{n}{ }^{\circ} 9$.

Marx, Karl. (1867-1894). El Capital. Crítica de la economía política (3 vol). FCE: México.

Merino, Raquel \& Rabadán, Rosa. 2002. Censored Translations in Franco's Spain: The TRACE Project-Theatre and Fiction (English-Spanish). TTR: traduction, terminologie, rédaction 15(2): 125-152.

Merriam-Webster Dictionary (2013). [en línea]. [ref. de 10 de diciembre 2014]. Disponible en internet. http://www.merriam-webster.com/dictionary/ censhorship [Acceso 06/01/2015].

New York Times (2005). [en línea]. [ref. de 10 de Diciembre de 2014]. Disponible en internet <www.nytimes.com/2005/01/31/international/ europe/31netherlands.html?_r=0> [Acceso 06/01/2015].

Rabadán, Rosa. (ed). 2000. Traducción y censura inglés-español: 1939-1985: Estudio preliminar. León: Universidad de León.

O'Connell, Eithne M. T. 2003. Minority Language Dubbing for Children. Screen Translation from German to Irish. Berna: Peter Lang.

Richart-Marset, Mabel. 2009. La alegría de transformar. Teorías de la traducción y teoría del doblaje audiovisual. Valencia: Tirant lo Blanch.

Richart-Marset, Mabel. 2012. Ideología y Traducción. Por un análisis genético del doblaje. Madrid: Biblioteca Nueva. 
Richart-Marset, Mabel. 2013. La caja negra y el mal de archivo: defensa de un análisis genético del doblaje cinematográfico. Trans. Revista de Traductología 17: 51-69.

Robyns, C. 1994. Translation as Discursive Identity. Poetic Today 15(3): 405428

Scandura, Gabriela L. 2004. Sex, Lies and TV: Censorship and Subtitling. Meta: Translators' Journal 49(1): 125-134.

Voloshinov, Valentin. 1992. El marxismo y la filosofia del lenguaje. Madrid: Alianza.

Zabalbeascoa, Patrick. 1994. Factors in dubbing televisión comedy. Perspectives. Studies in Translatology, 1: 89-100. 
